\title{
Exogenous salicylic acid alleviates the accumulation of pesticides and mitigates pesticide-induced oxidative stress in cucumber plants
}

\author{
Nan Zou ${ }^{1}$, Liu Ting ${ }^{1}$, Li Tong ${ }^{1}$, Zhang Yan $^{1}$, Li Lin $^{1}$, Liu Ke ${ }^{1}$, Yang Song ${ }^{1}$, An Shun ${ }^{2}$, and \\ Pan Ping ${ }^{2}$ \\ ${ }^{1}$ Shandong Agricultural University \\ ${ }^{2}$ China Agricultural University
}

May 13, 2020

\begin{abstract}
Salicylic acid (SA) is an important signal molecule, regulating oxidative stress response in plants. In this study, we evaluated the influences of SA (1mg L-1, 10mg L-1 and 50mg L-1) on the accumulation of clothianidin (CLO), dinotefuran (DFN) and difenoconazole (DFZ) (5mg L-1) and pesticide-induced (CLO-10mg L-1, DFN-20 mg L-1, and DFZ-10mg L-1) oxidative stress in cucumber plants. Exogenous SA at 10mg L-1 significantly reduced the half-lives of three pesticides in nutrient solution and prevented the accumulation of pesticides in roots and leaves. And the role of SA in reducing residues was related to the major accumulation sites of pesticides. By calculating the root concentration factor (RCF) and translocation factor (TF), we found that SA at 10mg L-1 reduced the ability of roots to absorb pesticides and enhanced the translocation ability from roots to leaves. Roots exposed to high concentrations of three pesticides could reduce biomass, low chlorophyll content, promote lipid peroxidation, and alter the activities of a range of antioxidant enzymes, respectively. Exogenous SA at low concentrations significantly mitigated these negative effects. Hence, we speculated that application of exogenous SA at $10 \mathrm{mg}$ L-1 could effectively alleviate the accumulation of pesticides and induce stress tolerance in cucumber planting systems.
\end{abstract}

\section{ABSTRACT:}

Salicylic acid (SA) is an important signal molecule, regulating oxidative stress response in plants. In this study, we evaluated the influences of SA $\left(1 \mathrm{mg} \mathrm{L}^{-1}, 10 \mathrm{mg} \mathrm{L}^{-1}\right.$ and $\left.50 \mathrm{mg} \mathrm{L}^{-1}\right)$ on the accumulation of clothianidin (CLO), dinotefuran (DFN) and difenoconazole (DFZ) $\left(5 \mathrm{mg} \mathrm{L}^{-1}\right)$ and pesticide-induced (CLO-10mg L $\mathrm{m}^{-1}$, DFN-20 mg L $\mathrm{m}^{-1}$, and DFZ-10mg L ${ }^{-1}$ ) oxidative stress in cucumber plants. Exogenous SA at $10 \mathrm{mg} \mathrm{L}^{-1}$ significantly reduced the half-lives of three pesticides in nutrient solution and prevented the accumulation of pesticides in roots and leaves. And the role of SA in reducing residues was related to the major accumulation sites of pesticides. By calculating the root concentration factor (RCF) and translocation factor (TF), we found that SA at $10 \mathrm{mg} \mathrm{L}^{-1}$ reduced the ability of roots to absorb pesticides and enhanced the translocation ability from roots to leaves. Roots exposed to high concentrations of three pesticides could reduce biomass, low chlorophyll content, promote lipid peroxidation, and alter the activities of a range of antioxidant enzymes, respectively. Exogenous SA at low concentrations significantly mitigated these negative effects. Hence, we speculated that application of exogenous SA at $10 \mathrm{mg} \mathrm{L}^{-1}$ could effectively alleviate the accumulation of pesticides and induce stress tolerance in cucumber planting systems.

Keywords: Pesticides, Cucumber, Uptake, Translocation, Salicylic acid, Oxidative stress

\section{Introduction}


As a kind of plant protection product, pesticides play an important role in controlling diseases, insects, weeds, and increasing yield of crops (J. Liang \& Tang, 2010). However, its misuse has caused a series of environmental safety and food safety problems. For example, some neonicotinoids have raised concerns about their toxicity to bees, which put them at risk of being banned (Jiang et al., 2018; Jiang, Zhang, Lin, Liu, \& $\mathrm{Mu}, 2019$ ). Moreover, overuse of pesticides may cause pesticide pollution in agricultural products as well as soil and water (K. Wang, Wu, \& Zhang, 2012). And once the excessive accumulation of pesticides will cause phytotoxicity by injuring the physiological structure of plants (Mahapatra, De, Banerjee, \& Roy, 2019). Therefore, it is necessary to investigate the uptake, translocation and accumulation behaviors of systemic pesticides in plants and make effective strategies to reduce pesticide stress.

The active expression of pesticides is closely related to its uptake and translocation behaviors in plants. On the one hand, the uptake and translocation behaviors of pesticides affect the efficacy and duration, which is beneficial to choose the application technology of pesticides (Huang et al., 2019); On the other hand, it is helpful to further understand the dynamic distribution and accumulation of pesticides in various parts of plants and clarify the dynamics residues of pesticides in the environment (Hingmire, Oulkar, Utture, Ahammed Shabeer, \& Banerjee, 2015; Utture et al., 2011). Previous studies have reported that the uptake and translocation behaviors of systemic pesticides in plants are related to their physical and chemical properties, such as octanol/water partition coefficient $\left(\log \mathrm{K}_{\mathrm{ow}}\right)$, water solubility and molecular weight (Y. Li, Long, et al., 2018; Namiki, Otani, Motoki, Seike, \& Iwafune, 2018; Qiu et al., 2016), but also are related to the plant species, growth conditions, growth stage, application method and other factors (Ge et al., 2016; Hwang, Lee, \& Kim, 2015; Y. Li, Yang, et al., 2018).

When plants subjected to various biological and abiotic stresses, a large number of reactive oxygen species (ROS) can accumulate in the cells, which can destroy the cell molecular structure and interfere with the physiological process of plants (Noctor, Mhamdi, \& Foyer, 2016). For defense, plants have a variety of complex enzymatic and non-enzymatic antioxidant systems that they can resist oxidative stress including superoxide dismutase (SOD), peroxidase (POD), catalase (CAT), ascorbate peroxidase (APX) and other enzymes and non-enzymatic substances they can remove different types ROS (Safari, Akramian, SalehiArjmand, \& Khadivi, 2019). As a result of human production activities, many wastes remained in the environment for a long time, which can produce stress responses to plants such as heavy metals, pesticides, and engineered nanomaterials (Lian et al., 2020; Rodriguez-Serrano et al., 2006; Safari et al., 2019). Salicylic acid (SA) is a well-known endogenous signaling molecule related to plants stress resistance (Q. J. Wang et al., 2016; X. Y. Zhao et al., 2020; X. Y. Zhao et al., 2019). When plants are in adverse environments, SA can regulate various physiological and biochemical processes of plants to alleviate stress (W. Y. Song, Peng, Shao, Shao, \& Yang, 2014; Q. Wang et al., 2013; Xu, Fan, Dong, Kong, \& Bai, 2014). It is worth noting that SA can inhibit the accumulation of pesticides in plants, which is vital for reducing pesticide residues and ensuring the safety of agricultural products (Kaya \& Yigit, 2014; C. Wang \& Zhang, 2017). For phytotoxicity caused by pesticides, most previous studies focused on exogenous SA to reduce the toxicity of herbicides on nontarget plants (Akbulut, Yigit, Kaya, \& Aktas, 2018; Kaya \& Doganlar, 2016). However, the regulatory functions of SA under commonly used systemic pesticide stress and the effects of exogenous $\mathrm{SA}$ on the accumulation of pesticides in various parts of the plants were rarely investigated.

Cucumber(Cucumis sativus L. ) is a widely cultivated cash crop in China. In the present study, the three pesticides, clothianidin (CLO), dinotefuran (DFN) and difenoconazole (DFZ) were selected as the representatives. CLO is a neonicotinoid insecticide with excellent systemic and osmotic activity that can be used as a soil, spray and seed treatment, for control of sucking and chewing insects (Jeschke, Nauen, Schindler, \& Elbert, 2011). DFN is a systemic neonicotinoid insecticide with translaminar activity, and it can be applied on foliage, soil and nursery boxes by spray, drench, broadcast and pricking-in-hole treatments (Corbel, Duchon, Zaim, \& Hougard, 2004). DFZ is a systemic fungicide of sterol demethylation inhibitors with a novel broad-range activity protecting the yield and crop quality by foliar application or seed treatment (Dong et al., 2013). The three pesticides all could be absorbed by plant roots, which can be used for soil treatment, but there are significant differences in water solubility and $\log \mathrm{K}_{\mathrm{ow}}$ of the three pesticides. The physical and chemical properties of these three pesticides are shown in Table S1. We investigated the 
effects of exogenous SA on the uptake, translocation and accumulation behaviors of these three pesticides in cucumber plants by measuring the concentration of pesticides in various parts of the cucumber plants and calculating the root concentration factor $(\mathrm{RCF})$ and translocation factor $(\mathrm{TF})$ values. Moreover, the effects of SA on oxidative stress induced by these three pesticides to the cucumber plants were also studied by measuring biomass, photosynthetic pigment content, antioxidants content and antioxidant enzyme activities. This study provides a new perspective to understand the uptake and translocation behaviors of pesticides and pesticide pollution in plants.

\section{Experimental Section}

\subsection{Chemicals and materials}

Certified pesticide standards of CLO (97\%), DFN (98\%), DFZ (97\%), and standards of SA (99.5 \%) were purchased from Aladdin Chemistry Co., Ltd. (Shanghai, China)

Reagents: Sodium chloride $(\mathrm{NaCl})$ and anhydrous magnesium sulfate $\left(\mathrm{MgSO}_{4}\right)$ were purchased from Sinopharm Chemical Reagent (Beijing, China). PSA $(40-63 \mu \mathrm{m})$ was obtained from Tianjin Bonna-Agela Technology Co., Ltd. (Tianjin, China). Acetonitrile (HPLC grade) was obtained from Fisher Chemicals (Fair Lawn, NJ, USA).

\subsection{Experiment design}

Plant cultivation: The seeds of cucumber were provided by the Xintai Yuyuan Seed Industry Co., Ltd (Shandong, China). Cucumber seeds were wrapped in wet gauze and placed in a petri dish to accelerate germination. When the seeds germinating, we transferred the seeds into a seedling tray and put one seed into each hole. The temperature of the greenhouse was 25 in the day and 20 at night. After growth 21 days, the young plants were used in pesticides exposure trials.

\subsubsection{Pesticide exposure experiments-uptake and translocation}

Hydroponic experiments: The concentration of three pesticides was set at $5 \mathrm{mg} \mathrm{L}^{-1}$, and the concentrations of SA were set at $1 \mathrm{mg} \mathrm{L}^{-1}, 10 \mathrm{mg} \mathrm{L}^{-1}$, and $50 \mathrm{mg} \mathrm{L}^{-1}$, respectively. CLO, DFN or DFZ was first dissolved in acetonitrile to form the stock standard solution, respectively. And then the standard stock solutions were diluted to the required concentration by ultrapure water. SA was dissolved and diluted with $20 \%$ methanol-water.

After germination, the cucumber seedlings were removed from the seedling tray, and the roots were washed by deionized water before transferred to hydroponic cultivation buckets with $0.25 \mathrm{~L}$ modified Hoagland nutrient solution in the greenhouse. The composition of the nutrient solution can be found inTable S2 . The growth conditions were the same as the plant cultivation conditions. And a total of 12 treatments were set in the experiment with 27 cucumber seedlings per treatment, the processing information for each test can be found in Table 1 . The hydroponic cultivation buckets were covered with aluminum foil to prevent algae growth and water evaporation. The nutrient solution was supplemented to the initial volume at 11 am every day.

Control experiments: Two control groups were included: nutrient solution with cucumber seedlings without pesticides was as the treatment of C1 group; and nutrient solution with CLO, DFN and DFZ but without cucumber seedlings were as the treatments of CLO-C2, DFN-C2 and DFZ-C2 groups, respectively.

Sample collection: Cucumber seedlings were grown for 28 days, nutrient solution and plant samples were collected at $0.25,1,3,5,7,10,14,21,28$ days after the transfer. The plants were divided into roots, stems and leaves for pesticide analysis. At each sampling time, three replicate samples were randomly taken. All samples were stored at -20 until analysis.

\subsubsection{Pesticide exposure experiments- oxidative stress in cucumber plants}

Single root exposure of CLO, DFN and DFZ:Hydroponic experiment conditions and plant growth conditions were the same as the "uptake and translocation." Given the tendency for repeated application 
of pesticides, a series of preliminary experiments using various concentrations of pesticides were carried to evaluated the cucumber growth parameters. When the root application of CLO at $10 \mathrm{mg} \mathrm{L}^{-1}$, DFN at $20 \mathrm{mg}$ $\mathrm{L}^{-1}$ and DFZ at $10 \mathrm{mg} \mathrm{L^{-1 }}$, the fresh biomass of cucumber plants significantly decreased, respectively. We estimated that at these concentrations, the three pesticides caused significant stress responses, respectively (Fig S1 ). Therefore, we set the concentration of CLO at $10 \mathrm{mg} \mathrm{L}^{-1}$, DFN at $20 \mathrm{mg} \mathrm{L}^{-1}$ and DFZ at $10 \mathrm{mg}$ $\mathrm{L}^{-1}$, and with SA supplementation at $1 \mathrm{mg} \mathrm{L}^{-1}, 10 \mathrm{mg} \mathrm{L}^{-1}$ and $50 \mathrm{mg} \mathrm{L}^{-1}$, the root, stem and leaf samples were collected after 10 days of growth, respectively. A total of 12 treatments were set in this part of experiment. The plants were grown in blank nutrient solution as a control group. After the root, stem and leaf samples were weighed, the root samples were stored at -80 until measured.

\subsection{Determination of CLO, DFN and DFZ in cucumber plants}

For "pesticide exposure experiments- uptake and translocation" part, the contents of pesticides in plant tissue samples were analyzed. The QuECHERS method was used to prepare nutrient solution and plant tissue samples (Ge et al., 2017). The specific sample preparation steps and instrumental analysis conditions are shown in the supplementary materials .

The recoveries of three pesticides in nutrient solution and plant tissues were used to verify the feasibility of the analytical method. External standard method was used for quantitative analysis. The results of quality assurance and quality control are shown in the supplementary materials .

\subsection{Determination of antioxidant enzyme activity}

The extraction of enzyme liquid was carried out according to the method described by Andrews et al. (2005). The method of SOD determination referred to Farouk and Al-Amri (2019). APX activity was determined by the reduction value of absorbance at $290 \mathrm{~nm}$ per unit time using the method of Kaya and Doganlar (2016). GST activity was tested according to Habig, Pabst, and Jakoby (1974). The specific measurement steps are shown in the supplementary materials .

\subsection{Determination of the total chlorophyll and $\mathrm{H}_{2} \mathrm{O}_{2}$ content in cucumber plants}

The pigment was extracted by methanol extraction following the method of L. Zhao et al. (2019). The specific measurement steps are shown in thesupplementary materials . The content of $\mathrm{H}_{2} \mathrm{O}_{2}$ in cucumber roots was determined by $\mathrm{H}_{2} \mathrm{O}_{2}$ kits.

\subsection{Determination of the malondialdehyde (MDA) content}

The level of lipid peroxidation was evaluated by the determination of malondialdehyde (MDA) content based on the method of Heath and Packer (1968). The specific measurement steps are shown in thesupplementary materials .

\subsection{Determination ofproline content}

The content of proline in plant roots was determined according to the method of Bates, Waldren, and Teare (1973). The specific measurement steps are shown in the supplementary materials .

\subsection{Data processing and statistical analysis}

In order to compare the difference in the behaviors of three pesticides between supplementing different concentrations of SA and without SA, the root concentration factor (RCF) and translocation factor (TF) were calculated. The root concentration factor $(\mathrm{RCF})$ was used to indicate the ability to absorb target compounds by plant roots in nutrient solution, $\mathrm{RCF}>1$ indicates that the compound is easily absorbed by the roots, and calculated as follows (Qiu et al., 2016): (Eqn 1)

$\mathrm{RCF}=\frac{\text { concentration in root }(\mathrm{mg} / \mathrm{kg})}{\text { concentration in nutrient solution }(\mathrm{mg} / \mathrm{L})}$

Translocation factors (TF) was used to indicate the ability of leaves and stems to transport target compounds from roots, $\mathrm{TF}>1$ indicates that the excellent capacity for stems and leaves to translocate the pesticides from roots, and calculated as follows (Ge et al., 2016): (Eqn 2 and Eqn 3) 


$$
\begin{aligned}
& \text { TFstem }=\frac{\text { concentration in stem }(\mathrm{mg} / \mathrm{kg})}{\text { concentration in root }(\mathrm{mg} / \mathrm{kg})} \\
& \text { TFleaf }=\frac{\text { concentration in leaf }(\mathrm{mg} / \mathrm{kg})}{\text { concentration in root }(\mathrm{mg} / \mathrm{kg})}
\end{aligned}
$$

The concentration of pesticides in nutrient solution was calculated using the first-order equation $\mathrm{C}_{t}=\mathrm{C}_{0} \mathrm{e}^{-\mathrm{kt}}$. The half-life was calculated by the equation $t_{1 / 2}=\ln 2 / \mathrm{k}$, where $\mathrm{C}_{t}$ is the concentration of target pesticides at time $\mathrm{t}$ (days), $\mathrm{C}_{0}$ is the concentration of target pesticides at the initial time, and $\mathrm{k}$ is the first-order rate constant $\left(\right.$ day $\left.^{-1}\right)$.

An independent sample t-test was used to compare the differences between different treatments and pesticides. All statistical analyses were statistical significance at the 0.05 level.

\section{Results}

\subsection{Dissipation dynamics of pesticides in nutrient solution.}

The dissipation dynamic of CLO, DFN and DFZ in nutrient solution during the experimental period were shown in Fig $1 \mathbf{A}$, and the half-lives $\left(t_{1 / 2}\right)$ of the pesticides in nutrient solution were shown in Table 2 - None of the target pesticides were detected in the control group C1. The three pesticides showed the same dissipation trend, and all of them followed the first-order kinetics. Approximately $80-90 \%$ of pesticides were degraded in nutrient solution during the 28-day experimental period, and the dissipation half-lives of CLO, DFN and DFZ were 6.3, 11.5 and 13.8 days, respectively. However, in unplanted nutrient solution, the dissipation half-lives of CLO, DFN and DFZ were 12.4, 15.8 and 18.2 days, respectively.

The effects of exogenous SA on the dissipation dynamics of pesticides are shown in Fig $\mathbf{1} \mathbf{B}, \mathbf{C}, \mathbf{D}$ and the half-lives $\left(\mathrm{t}_{1 / 2}\right)$ are shown in Table $\mathbf{2}$. For CLO, the half-lives decreased by $8 \%$ and $35 \%$ with supplementing $\mathrm{SA}$ at $1 \mathrm{mg} \mathrm{L}^{-1}$ and $10 \mathrm{mg} \mathrm{L}^{-1}$, respectively, compared with the without SA treatments. For DFN, the halflives decreased by $14 \%$ and $40 \%$ with supplementing SA at $1 \mathrm{mg} \mathrm{L}^{-1}$ and $10 \mathrm{mg} \mathrm{L}^{-1}$, respectively, compared with the without SA treatments. For DFZ, the half-lives decreased by $8 \%, 61 \%$ and $28 \%$ with supplementing $\mathrm{SA}$ at $1 \mathrm{mg} \mathrm{L}^{-1}, 10 \mathrm{mg} \mathrm{L}^{-1}$ and $50 \mathrm{mg} \mathrm{L}^{-1}$, respectively, compared with the without $\mathrm{SA}$ treatments.

\subsection{Dynamic distribution, translocation and accumulation of pesticides in cucumber plants}

The dynamic distribution and accumulation of CLO, DFN and DFZ in cucumber plants are shown in Fig. 2A under hydroponic experiments. For CLO and DFN, the concentrations of pesticides in leaves were much higher than those in roots and stems, indicating that CLO and DFN were mainly accumulated in leaves, and these have great upward conductivity, respectively. For DFZ, the concentration of pesticide in roots was much higher than that in stems and leaves, indicating that DFZ could be mainly accumulated in roots, and its upward conductivity was poor.

The effects of exogenous SA on the distribution of three pesticides in the roots, stems and leaves of cucumber plants are shown in Fig. 2 B, C, D . From the charts, it can be seen that with SA supplementation the concentrations of three pesticides in roots, stems and leaves of cucumber plants basically showed a decreasing trend during the 28 days of growth. To assess the overall effects of SA on the distribution of three pesticides in different parts of cucumber plants, the mean residues of three pesticides in different parts of cucumber plants after 28 days of growth were calculated, respectively (Fig. 3). With SA supplementation at $1 \mathrm{mg} \mathrm{L}^{-1}$, the concentration of CLO and DFN in roots and leaves significantly decreased by $27 \%, 18 \%$ and $23 \%, 19 \%$, respectively, compared with the treatments of CLO and DFN alone; with SA supplementation at $10 \mathrm{mg} \mathrm{L}^{-1}$, the concentration of CLO and DFN in roots and leaves significantly decreased by $56 \%, 28 \%$ and $46 \%, 25 \%$, respectively, compared with the treatments of CLO and DFN alone. With SA supplementation at 50mg L $\mathrm{L}^{-1}$, the concentration of CLO in roots and leaves significantly decreased by $23 \%$ and $20 \%$, respectively, compared with the treatment of CLO alone. For DFZ, the concentration in roots significantly decreased by $11 \%$ and $40 \%$ after addition of SA at $1 \mathrm{mg} \mathrm{L}^{-1}$ and $10 \mathrm{mg} \mathrm{L}^{-1}$, respectively, compared with the treatment of DFZ alone.

\subsection{Root concentration factor and translocation concentration factor}


To further explore the difference in the uptake and translocation of three pesticides with SA or without SA in the cucumber plants, the root concentration factor (RCF) and translocation factor (TF) were analyzed. The average RCF values of three pesticides are summarized inTable $\mathbf{3}$, and the dynamic RCF values of three pesticides during 28-days of exposure are shown in Table S5 . The RCF value ranged from 0.15 to 3.12 for CLO, from 0.2 to 1.11 for DFN, from 26.10 to 148.30 for DFZ during 28-days of exposure. The average RCF values for CLO, DFN, DFZ were 1.07, 0.64 and 52.19, respectively. Whereas with SA supplementing, the average RCF values for the three pesticides were all decreased. For CLO, the average RCF values were significantly decreased by $49 \%, 35 \%$ and $26 \%$ with addition of SA at $1 \mathrm{mg} \mathrm{L}^{-1}, 10 \mathrm{mg} \mathrm{L}^{-1}$ and $50 \mathrm{mg} \mathrm{L}^{-1}$, respectively, compared with the treatment of CLO alone. For DFN, the average RCF values were decreased by $6.25 \%$ and $11 \%$ with addition of SA at $1 \mathrm{mg} \mathrm{L}^{-1}$ and $10 \mathrm{mg} \mathrm{L}^{-1}$, respectively, compared with the treatment of DFN alone. For DFZ, the average RCF value was significantly decreased by $16 \%$ with addition of SA at $10 \mathrm{mg}^{-1}$ compared with the treatment of DFZ alone.

The average TF values of three pesticides are summarized inTable 4 , and the dynamic TF values of three pesticides during 28-days of exposure are shown in Table $\mathbf{S} 6$ and $\mathbf{S 7}$. The average $\mathrm{TF}_{\text {stem }}$ and $\mathrm{TF}_{\text {leaf }}$ of CLO, DFN, DFZ were 0.98, 0.69, 0.02 and 8.81, 8.03, 0.005, respectively. In addition to CLO, no significant differences were found for $\mathrm{TF}_{\text {stem }}$ between the treatment groups with SA supplementation and the groups without SA supplementation, which again demonstrated that pesticides migrated up via the transpiration stream and eventually accumulated in the leaves, and the stems were just a bridge for pesticides upward conduction and reached equilibrium with transpiration stream (Volpe, Marani, Albertson, \& Katul, 2013). For CLO, the $\mathrm{TF}_{\text {leaf }}$ values were significantly increased by $102 \%, 130 \%$ and $31 \%$ after adding SA at $1 \mathrm{mg}$ $\mathrm{L}^{-1}, 10 \mathrm{mg} \mathrm{L}^{-1}$ and $50 \mathrm{mg} \mathrm{L}^{-1}$, respectively, compared with the treatment of CLO alone. For DFN, the TF leaf values were significantly increased by $77 \%$ and $43 \%$ after adding SA at $10 \mathrm{mg} \mathrm{L}^{-1}$ and $50 \mathrm{mg} \mathrm{L}^{-1}$, respectively, compared with the treatment of DFN alone. For DFZ, the $\mathrm{TF}_{\text {leaf }}$ values were significantly increased by $160 \%$ and $120 \%$ after adding SA at $10 \mathrm{mg} \mathrm{L}^{-1}$ and $50 \mathrm{mg} \mathrm{L}^{-1}$, respectively, compared with the treatment of DFZ alone.

\subsection{Effects of exogenous salicylic acid on oxidative stress in cucumber plants}

\subsubsection{Fresh biomass and total chlorophyll content}

Single root exposure of CLO (10 $\left.\mathrm{mg} \mathrm{L}^{-1}\right)$, DFN (20 mg L-1) and DFZ (10 mg L $\left.\mathrm{m}^{-1}\right)$ significantly affected the fresh biomass of plants and total chlorophyll content (Fig. $4 \mathbf{A}$ and $\mathbf{B}$ ). Compared with the controls, for CLO, DFN and DFZ, the values of fresh biomass of plants decreased by $15.4 \%, 24.5 \%$ and $53.8 \%$ after single root exposure, respectively (Fig. $4 \mathbf{A}$ ); the values of total chlorophyll content decreased by 26.2 \%, $28 \%, 31 \%$, respectively (Fig. 4 B ). As shown in Fig. 4 Aand B , among the treatments with SA supplementation, the fresh biomass of plants increased compared with the without SA treatments. With SA supplementation at $1 \mathrm{mg} \mathrm{L}^{-1}$, the fresh biomass of plants increased by $25.5 \%, 1.18 \%, 66.7 \%$ compared to the single root exposure of CLO, DFN and DFZ treatments, respectively. With SA supplementation at 10 $\mathrm{mg} \mathrm{L} \mathrm{L}^{-1}$, the fresh biomass of plants significantly increased by $33.8 \%, 18.9 \%, 74.6 \%$ compared to the single root exposure of CLO, DFN and DFZ treatments, respectively. (Fig. 4 A ). Similarly, compared with the treatments with CLO, DFN or DFZ alone, SA at $1 \mathrm{mg} \mathrm{L}^{-1}$ and $10 \mathrm{mg} \mathrm{L}^{-1}$ significantly improved the total chlorophyll content, which increased by $47.1 \%, 124 \%, 144 \%$ and $41.1 \%, 150 \%, 113 \%$ (Fig. 4 B ).

\subsubsection{ROS generation and proline content}

The values of $\mathrm{H}_{2} \mathrm{O}_{2}$ content and proline content are shown in Fig. $4 \mathbf{C}, \mathbf{D}$. From the data in Fig. $4 \mathbf{C}$, it could be seen that after single root exposure to CLO, DFN and DFZ, the values of $\mathrm{H}_{2} \mathrm{O}_{2}$ content increased by $313 \%, 300 \%$ and $424 \%$, respectively, compared with the controls. Also, the low concentration $\left(1 \mathrm{mg} \mathrm{L}^{-1}\right.$ and $10 \mathrm{mg} \mathrm{L}^{-1}$ ) of SA have significant effects on reducing the $\mathrm{H}_{2} \mathrm{O}_{2}$ content of roots. With $\mathrm{SA}$ supplementation at $1 \mathrm{mg} \mathrm{L}^{-1}$, the $\mathrm{H}_{2} \mathrm{O}_{2}$ content in roots significantly decreased by $74 \%, 62 \%$ and $52 \%$, respectively, compared with the single root exposure of CLO, DFN and DFZ treatments. With SA supplementation at $10 \mathrm{mg} \mathrm{L}^{-1}$, the $\mathrm{H}_{2} \mathrm{O}_{2}$ content in roots significantly decreased by $78 \%, 82 \%$ and $62 \%$, respectively, compared with the single root exposure of CLO, DFN and DFZ treatments (Fig. 4 C ). 
In the present study, it was found that the three pesticides all enhanced accumulation of proline and more increased when the SA at $1 \mathrm{mg} \mathrm{L}^{-1}$ and $10 \mathrm{mg} \mathrm{L}^{-1}$ were supplemented. With SA supplementation at $1 \mathrm{mg} \mathrm{L}^{-1}$, the proline content in roots significantly in- creased by $35 \%, 29 \%$ and $35 \%$, respectively, compared with the single root exposure of CLO, DFN and DFZ treatments. With SA supplementation at $10 \mathrm{mg} \mathrm{L}^{-1}$, the proline content in roots significantly increased by $44 \%, 52 \%$ and $83 \%$, respectively, compared with the single root exposure of CLO, DFN and DFZ treatments (Fig. 4 D ).

\subsubsection{Antioxidant enzymes assays and lipid peroxidation}

The activities of SOD, APX and GST in roots were markedly affected under CLO, DFN and DFZ treatments compared with the controls, respectively. The SOD activity increased by $150 \%, 191 \%$ and $210 \%$ at the single root exposure of CLO, DFN, and DFZ treatments, respectively, compared with the controls, while APX activity was significantly inhibited (Fig. 4E, F ). Similarly, single root exposure to CLO, DFN, and DFZ also led to increasing GST activity, respectively (Fig.4 G ). From the dates in Fig. 4 E, F, G , exogenous SA also could alter the antioxidant enzyme activities. The SOD activity significantly decreased in the roots of cucumber plants treated with $1 \mathrm{mg} \mathrm{L}^{-1}$ and $10 \mathrm{mg} \mathrm{L}^{-1} \mathrm{SA}$ compared with the treatments with pesticides alone, and it was similar to the control groups (Fig. $4 \mathbf{E}$ ). Similarly, SA at $1 \mathrm{mg} \mathrm{L}^{-1}$ and $10 \mathrm{mg} \mathrm{L}^{-1}$ also increased the APX activity, suggesting that the phytotoxicity caused by three pesticides were alleviated, respectively (Fig. $4 \mathbf{F}$ ). With supplementing exogenous SA $\left(1 \mathrm{mg} \mathrm{L}^{-1}\right.$ and $\left.10 \mathrm{mg} \mathrm{L}^{-1}\right)$, GST activity in roots was elevated, which was beneficial to promoting pesticide metabolism and alleviating phytotoxicity (Han, Mhamdi, Chaouch, \& Noctor, 2013; Kaya \& Doganlar, 2016).

As for single root of CLO, DFN, and DFZ exposure, MDA contents in cucumber roots significantly increased by $40 \%, 59 \%$ and $67 \%$, respectively, compared with the unstressed plants (Fig. $4 \mathbf{H})$. With SA supplementation at $1 \mathrm{mg} \mathrm{L}^{-1}$, the MDA content in roots significantly decreased by $56 \%, 57 \%$ and $37 \%$, respectively, compared with the single root exposure of CLO, DFN and DFZ treatments. With SA supplementation at $10 \mathrm{mg} \mathrm{L}^{-1}$, the MDA content in roots significantly decreased by $61 \%, 61 \%$ and $56 \%$, respectively, compared with the single root exposure of CLO, DFN and DFZ treatments.

\section{Discussion}

\subsection{The dissipation and accumulation behaviors of pesticides}

In this study, the half-lives of individual pesticides in planted nutrient solution were significantly shorter than that in unplanted nutrient solution. Plant intake was an important factor, and previous studies have shown that the half-lives of pesticides were relevant to the factors as the cultivation modes of plants, the existence of plants, and soil types (Lockridge, Verdier, \& Schopfer, 2019; Šudoma et al., 2019). Lv et al. (2016) found that during the experimental period, the $\mathrm{pH}$ level of the unplanted systems keep constant, but the $\mathrm{pH}$ of the planted systems significantly decreased. Plants can secrete secondary metabolites during the growth period, including low-molecular-weight substances (e.g., organic acids, amino acids, and fatty acids) and high-molecular-weight substances (e.g., polysaccharides and proteins) (L. Zhao et al., 2016). Substances that produced by plant roots metabolism might be responsible for changes in $\mathrm{pH}$ of nutrient solutions. Therefore, the $\mathrm{pH}$ level of nutrient solution might be one reason for the change of half-lives.

The CLO and DFN were mainly accumulated in leaves, and the DFZ was mainly accumulated in roots, which could be attributed to the water solubility and partition coefficient octanol/water $\left(\log K_{\text {ow }}\right)$ of the pesticides and differences in physiological structure between organs (Ge et al., 2016; Qiu et al., 2016). This finding was in agreement with the previous result, which showed that the concentrations of imidacloprid and thiamethoxam detected in rice leaves were higher than roots, but for difenoconazole, the concentration detected in rice roots was higher than leaves (Ge et al., 2017).

The RCF values of DFZ was highest, followed by CLO and DFZ. The larger the $\log \mathrm{K}_{\text {ow }}$ of pesticide, the easier it is to accumulate in the organs with more lipids. The order of lipid content of root, stem and leaf was root $>$ stem > leaf (Qiu et al., 2016). Thus, DFZ was more easily accumulated in the roots of cucumber plants. Previous studies have shown that the RCF values increased with increasing $\log \mathrm{K}_{\mathrm{ow}}$ values 
of pesticides, which was in accord with our results (Namiki et al., 2018; Qiu et al., 2016). Moreover, among the three pesticides, the highest TF value was the CLO followed in declining order by DFN and DFZ. The higher the solubility of pesticide, the easier it is to accumulate in the leaves (Qiu et al., 2016). The $\log K_{\mathrm{ow}}$ of DFZ was higher, while water solubility was poorer than CLO and DFN. Thus, the $\mathrm{TF}_{\text {stem }}$ and $\mathrm{TF}_{\text {leaf }}$ of DFZ were all lower than CLO and DFN, which again indicating that DFZ mainly accumulated in roots, and its upward migration ability was weak. The $\log \mathrm{K}_{\text {ow }}$ of CLO and DFN was comparative, and the $\mathrm{TF}_{\text {stem }}$ and $\mathrm{TF}_{\text {leaf }}$ was similar, respectively. For CLO and $\mathrm{DFN}, \mathrm{TF}_{\text {leaf }}$ were much higher than $\mathrm{TF}_{\text {stem }}$, indicating that both had stronger ability to migrate to the leaves, which could possibly be related to the higher water content in the leaves.

\subsection{The effect of exogenous SA on the behaviors of pesticides}

The effect of exogenous SA on pesticides half-lives depended on its concentrations. In the present study,

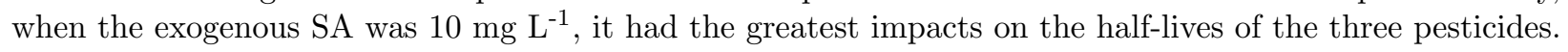
In addition, among the three pesticides, addition of SA at three concentrations all reduced the half-lives of DFZ in nutrient solution. And with supplementing SA at $10 \mathrm{mg} \mathrm{L}^{-1}$, the half-lives were reduced by more than half compared with the without SA treatments, which indicating that exogenous SA has the strongest effects on promoting the degradation of DFZ in nutrient solution. This might be related to the physical and chemical properties of pesticides. Importantly, the lower half-lives of individual pesticides mean that they keep shorter time in the environment, which can alleviate environmental pressure (Mohapatra et al., 2019).

Addition of SA at three concentrations all could block the accumulation of three pesticides in various parts of cucumber plants except for DFZ with SA supplementation at $50 \mathrm{mg} \mathrm{L}^{-1}$. When the SA was $1 \mathrm{mg} \mathrm{L}^{-1}$ and $10 \mathrm{mg}$ $\mathrm{L}^{-1}$, the inhibition of accumulation of the three pesticides was the most significant. Therefore, exogenous SA could prevent the accumulation of pesticides in plants, but had a dose effect. Previous study had shown that SA could reduce residues by promoting the intracellular herbicides catabolism (Y. C. Lu, Zhang, \& Yang, 2015). Noteworthy, addition of SA at $1 \mathrm{mg} \mathrm{L}^{-1}$ and $10 \mathrm{mg} \mathrm{L}^{-1}$ significantly reduced the concentrations of CLO and DFN in roots and leaves, respectively; but for DFZ, the concentration was significantly reduced in roots. For these phenomena, we speculated that it might be related to the accumulation behaviors of three pesticides in various parts of cucumber plants. And the effects of SA suppressing the pesticide entry into plant tissues might be related to the concentrations of pesticides (Kaya \& Yigit, 2014). Exogenous SA played the strongest role in promoting the degradation of pesticides in the sites with high concentration of pesticides. This idea could be proved again by showing that when SA was $10 \mathrm{mg} \mathrm{L}^{-1}$, the concentration of DFZ in the root was $18.70 \mathrm{mg} \mathrm{kg}^{-1}$, equivalent to $60 \%$ of the without SA treatments, which also indicated that exogenous SA had the greatest effect on reducing the DFZ residue in cucumber plants. In summary, the role of SA in reducing pesticide residues in a particular plant might be related to the major sites of accumulation, which provided a basis for selecting the application site of SA on the plants.

Addition of SA at $10 \mathrm{mg} \mathrm{L}^{-1}$, the RCF values of three pesticides all decreased, indicating that SA can inhibit pesticide uptake by roots and impaired the ability to accumulate pesticides. The $\mathrm{TF}_{\text {leaf }}$ values of three pesticides all improved after application of SA, indicating that the pesticides moved faster in cucumber plants than the without SA treatments. In our study, we found that SA can improve the upward migration ability of three pesticides. It was difficult to explain this result, but it might be related to the change of pesticide behavior and pesticide metabolism level in plants after the addition of SA (Kong, Dong, Xu, Liu, \& Bai, 2014). This finding also accorded with the earlier research, which showed that with SA supplementation, the TF value of isoproturon in wheat plants was higher than the without SA treatments (Yi Chen Lu et al., 2014).

\subsection{The role of exogenous SA in pesticide-induced oxidative stress in cucumber plants}

Previous studies indicated that excessive long-term application of pesticides could produce phytotoxicity once it exceeds the limits of non-target plant, which would affect plant growth by decreasing biomass and chlorophyll content and so on (Kaya \& Yigit, 2014; C. Wang \& Zhang, 2017). The roots system could absorb and transport water and nutrients to ensure the growth of the plants (Yu et al., 2020). When the plant roots 
are exposed to excessive pesticides, the physiological structure of the roots can be damaged, resulting in slow growth (C. Wang \& Zhang, 2017). Notably, compared with CLO and DFN, the fresh biomass of plants decreased by more than half when single root exposure of DFZ, which possibly due to the more residue of DFZ in the roots. After single root exposure of DFZ, the root morphology of cucumber plants changed compared with the control groups, which mainly showed that the lateral root decreased, the root volume increased, the diameter increased, and the root length became shorter (Fig. S2). In this study, the fresh biomass and total chlorophyll content significantly increased with SA supplementation at $1 \mathrm{mg} \mathrm{L}^{-1}$ and $10 \mathrm{mg}$ $\mathrm{L}^{-1}$ compared with the treatments of pesticides alone, respectively. Previous studies have demonstrated that low concentration of SA promoted plants growth, while high concentration of SA inhibited plants growth and low concentration of SA also could increase chlorophyll content (Kong, Dong, Zhang, et al., 2014; Pasternak et al., 2019; Y. Song et al., 2016).

Single root exposure of CLO, DFN and DFZ, the $\mathrm{H}_{2} \mathrm{O}_{2}$ content in cucumber roots significantly increased, indicating that the ROS balance in the plants was out of balance and might have a toxic effect on the plants(J. Xu et al., 2014). Similarly, it was also reported that some herbicides markedly increased the $\mathrm{H}_{2} \mathrm{O}_{2}$ content in non-target plants (Q. Li et al., 2019; Spormann, Soares, \& Fidalgo, 2019). However, the ROS imbalance of cucumber plants was alleviated by exogenous SA $\left(1 \mathrm{mg} \mathrm{L}^{-1}\right.$ and $\left.10 \mathrm{mg} \mathrm{L}^{-1}\right)$. Similarly, the research showed that application of $5 \mathrm{mg} \mathrm{L}^{-1}$ exogenous SA significantly eased the phytotoxicity of wheat inducing by isoproturon and also reduced the abundance of $\mathrm{O}^{--}$and $\mathrm{H}_{2} \mathrm{O}_{2}$ (L. Liang, Lu, \& Yang, 2012). Consistent with our results, exogenous SA had also been reported to increase the content of free proline in a variety of stressed plants (Q. Li et al., 2019; S. Liu, Dong, Xu, \& Kong, 2013; Safari et al., 2019). Proline is a small molecular organic solvent, which is widely found in plants in a free state. It can regulate cell osmotic pressure, stabilize sub-cellular structures such as membranes and proteins, remove reactive oxygen species and other (Ashraf \& Foolad, 2007). It also has been proved that free proline can remove reactive oxygen species caused by heavy metal Hg contamination (F. Wang, Zeng, Sun, \& Zhu, 2008). This fact was in accord with our study that as low concentration of SA-induced the increasing level of free proline coincided with the decreasing trend of $\mathrm{H}_{2} \mathrm{O}_{2}$ content in pesticides-stressed plants. Hence, increasing proline accumulation appeared to be an adaptive response which enhanced plants resistance to the pesticide stress.

Adverse environmental conditions stimulated the plants to induce oxidative stress and increased the activity of antioxidant enzymes to withstand stress (Akbulut et al., 2018; Lian et al., 2020). Exogenous SA at low concentrations also regulated antioxidant enzyme activities to resist stress (Kong, Dong, Xu, et al., 2014). In this study, after addition of SA at $1 \mathrm{mg} \mathrm{L}^{-1}$ and $10 \mathrm{mg} \mathrm{L}^{-1}$, the activities of APX and GST increased compared with the treatments of pesticides alone, respectively, and the SOD activity returned to the control level. Malondialdehyde (MDA) is the primary substance produced during lipid peroxidation, serving as an indicator of oxidative damage of membrane lipids. Under pesticide stress, cucumber plants treated with exogenous SA had lower MDA content than untreated ones. These results indicated the critical role of SA in plants resistance to stress and reduction of oxidative damage. This finding was further verified by the positive role of exogenous SA on the antioxidant enzyme activities and proline content. It has also been reported that exogenous SA can lower MDA content in other plants under stress of pesticides, heavy metals and nanomaterials (Safari et al., 2019; C. Wang \& Zhang, 2017).

\subsection{Mechanisms of alleviates phytotoxicity by exogenous SA}

In our study, three concentrations of exogenous SA were supplemented to assess the effects of SA on pesticides-induced oxidative stress in cucumber plants. Based on the above results, we found that low concentration of SA (1mg L $\mathrm{m}^{-1}$ and $\left.10 \mathrm{mg} \mathrm{L}^{-1}\right)$ had significant effects on relieving oxidative stress of cucumber plants induced by the three pesticides. Whereas, high concentration of exogenous SA (50 $\left.\mathrm{mg} \mathrm{L}^{-1}\right)$ had little effect on alleviating oxidative stress of cucumber plants. Therefore, the effects of exogenous SA on reducing oxidative stress depends on its concentrations. In accordance with the present results, previous studies have demonstrated that low concentration of SA can improve the tolerance of plants to adversity. In contrast, high concentration of SA induced a higher level of oxidative stress, leading to a decrease in tolerance to environmental stress (Bai, Dong, Kong, Xu, \& Liu, 2014; Z. Liu, Ding, Wang, Ye, \& Zhu, 2016; Pasternak 
et al., 2019). In the previous part of this study, we found that exogenous SA could impair the absorption capacity of roots to pesticides and thus reduce the accumulation of pesticides in cucumber plants. These results matched those observed in earlier studies. SA could reduce the accumulation of chlorpyrifos in wheat plants by decreasing uptake and translocation abilities of chlorpyrifos (C. Wang \& Zhang, 2017). SA could reduce the accumulation of isoproturon in wheat by promoting its degradation (L. Liang et al., 2012; Yi Chen $\mathrm{Lu}$ et al., 2014). SA could reduce the residual of flurochloridone in sunflower leaves by the foliar treatment (Kaya \& Yigit, 2014). SA was able to reduce the concentration of thiamethoxam, hymexazol and chlorantraniliprole in roots and leaves of cucumber plants and the uptake ability of roots, the bioconcentration ability of plants, and the translocation ability from roots to leaves were weakened (T. Liu et al., 2020). Taken together, we speculated that SA mitigated phytotoxicity by weakening the uptake ability of pesticides in plants and enhancing the capacity of antioxidative stress. However, the exact mechanism of SA on plant stress resistance needs to be further illuminated.

\section{Conclusions}

This study showed that exogenous SA $\left(10 \mathrm{mg} \mathrm{L}^{-1}\right)$ could promote the degradation of three pesticides in nutrient solution and suppress the accumulation of three pesticides in roots and leaves. Noteworthy, the role of SA in reducing pesticide residues was related to the accumulation sites of cucumber plants. Through the calculation of root concentration factor (RCF) and translocation factor (TF), it was found that exogenous SA (10mg L $\left.{ }^{-1}\right)$ significantly weakened the absorption capacity of roots to the three pesticides. Whereas, the translocation capacity of the three pesticides in cucumber plants were enhanced with three concentrations of SA supplementation. According to our study, single root exposure of three pesticides all caused phytotoxicity, which showed that the plants biomass decreased, chlorophyll synthesis was inhibited, proline accumulation increased, lipid peroxidation was promoted, and the activities of antioxidant enzyme (SOD, APX and GST) was destroyed, respectively. However, these adverse effects could be alleviated by supplementing with appropriate concentration of exogenous SA $\left(1 \mathrm{mg} \mathrm{L}^{-1}\right.$ and $\left.10 \mathrm{mg} \mathrm{L}^{-1}\right)$. This present study provided evidence that SA could reduce the accumulation of pesticides in plants and provided a basis for the application of exogenous SA in agricultural production. However, the exact interaction mechanism between pesticides and $\mathrm{SA}$ in plants needs to be further elucidated.

\section{Acknowledgement}

This work was supported by National Natural Science Foundation of China (31801781), Guangxi Special Fund Project (AA17204043-1), Natural Science Foundation of Shandong Province (ZR2018BC038), and National Key R\&D Program of China (2016YFD0200206).

\section{References}

Akbulut, G. B., Yigit, E., Kaya, A., \& Aktas, A. (2018). Effects of salicylic acid and organic selenium on wheat (Triticum aestivum L.) exposed to fenoxaprop-p-ethyl. Ecotoxicology and Environmental Safety, 148 , 901-909. doi:10.1016/j.ecoenv.2017.11.053

Andrews, C. J., Cummins, I., Skipsey, M., Grundy, N. M., Jepson, I., Townson, J., \& Edwards, R. (2005). Purification and characterisation of a family of glutathione transferases with roles in herbicide detoxification in soybean (Glycine max L.); selective enhancement by herbicides and herbicide safeners. Pesticide Biochemistry and Physiology, 82 (3), 205-219. doi:10.1016/j.pestbp.2004.11.009

Ashraf, M., \& Foolad, M. R. (2007). Roles of glycine betaine and proline in improving plant abiotic stress resistance.Environmental and Experimental Botany, 59 (2), 206-216. doi:10.1016/j.envexpbot.2005.12.006

Bai, X., Dong, Y., Kong, J., u, L., \& Liu, S. (2014). Effects of application of salicylic acid alleviates cadmium toxicity in perennial ryegrass. Plant Growth Regulation, 75 (3), 695-706. doi:10.1007/s10725-014-9971-3

Bates, L. S., Waldren, R. P., \& Teare, I. D. (1973). Rapid Determination of Free Proline for Water-Stress Studies. plant soil, 39 (1), 205-207. 
Corbel, V., Duchon, S., Zaim, M., \& Hougard, J. M. (2004). Dinotefuran: a potential neonicotinoid insecticide against resistant mosquitoes. J Med Entomol, 41 (4), 712-717. doi:10.1603/0022-2585-41.4.712

Dong, F., Li, J., Chankvetadze, B., Cheng, Y., Xu, J., Liu, X., . . . Zheng, Y. (2013). Chiral triazole fungicide difenoconazole: absolute stereochemistry, stereoselective bioactivity, aquatic toxicity, and environmental behavior in vegetables and soil. Environ Sci Technol, 47 (7), 3386-3394. doi:10.1021/es304982m

Farouk, S., \& Al-Amri, S. M. (2019). Exogenous melatonin-mediated modulation of arsenic tolerance with improved accretion of secondary metabolite production, activating antioxidant capacity and improved chloroplast ultrastructure in rosemary herb. Ecotoxicol Environ Saf, 180, 333-347. doi:10.1016/j.ecoenv.2019.05.021

Ge, J., Cui, K., Yan, H., Li, Y., Chai, Y., Liu, X., . . . Yu, X. (2017). Uptake and translocation of imidacloprid, thiamethoxam and difenoconazole in rice plants. Environ Pollut, 226 , 479-485. doi:10.1016/j.envpol.2017.04.043

Ge, J., Lu, M., Wang, D., Zhang, Z., Liu, X., \& Yu, X. (2016). Dissipation and distribution of chlorpyrifos in selected vegetables through foliage and root uptake. Chemosphere, 144 , 201-206. doi:10.1016/j.chemosphere.2015.08.072

Habig, W. H., Pabst, M. J., \& Jakoby, W. B. J. J. b. c. (1974). Glutathione S-transferase, The first enzymatic step in mercapturic acid formation. 249 (22), 7130-7139.

Han, Y., Mhamdi, A., Chaouch, S., \& Noctor, G. (2013). Regulation of basal and oxidative stresstriggered jasmonic acid-related gene expression by glutathione. Plant Cell Environ, 36 (6), 1135-1146. doi: $10.1111 /$ pce. 12048

Heath, R. L., \& Packer, L. (1968). Photoperoxidation in isolated chloroplasts. II. Role of electron transfer. Arch Biochem Biophys, 125 (3), 850-857. doi:10.1016/0003-9861(68)90523-7

Hingmire, S., Oulkar, D. P., Utture, S. C., Ahammed Shabeer, T. P., \& Banerjee, K. (2015). Residue analysis of fipronil and difenoconazole in okra by liquid chromatography tandem mass spectrometry and their food safety evaluation. Food Chem, 176 , 145-151. doi:10.1016/j.foodchem.2014.12.049

Huang, X. P., Luo, J., Song, Y. F., Li, B. X., Mu, W., \& Liu, F. (2019). Favorable Bioactivity of the SDHI Fungicide Benzovindiflupyr Against Sclerotinia sclerotiorum Mycelial Growth, Sclerotial Production, and Myceliogenic and Carpogenic Germination of Sclerotia. Plant Dis, 103 (7), 1613-1620. doi:10.1094/PDIS05-18-0729-RE

Hwang, J. I., Lee, S. E., \& Kim, J. E. (2015). Plant Uptake and Distribution of Endosulfan and Its Sulfate Metabolite Persisted in Soil.PLoS One, 10 (11), e0141728. doi:10.1371/journal.pone.0141728

Jeschke, P., Nauen, R., Schindler, M., \& Elbert, A. (2011). Overview of the status and global strategy for neonicotinoids. J Agric Food Chem, 59 (7), 2897-2908. doi:10.1021/jf101303g

Jiang, J., Ma, D., Zou, N., Yu, X., Zhang, Z., Liu, F., \& Mu, W. (2018). Concentrations of imidacloprid and thiamethoxam in pollen, nectar and leaves from seed-dressed cotton crops and their potential risk to honeybees (Apis mellifera L.). Chemosphere, 201 , 159-167. doi:10.1016/j.chemosphere.2018.02.168

Jiang, J., Zhang, Z., Lin, J., Liu, F., \& Mu, W. (2019). The minimally effective dosages of nitenpyram and thiamethoxam seed treatments against aphids (Aphis gossypii Glover) and their potential exposure risks to honeybees (Apis mellifera). Sci Total Environ, 666 , 68-78. doi:10.1016/j.scitotenv.2019.02.156

Kaya, A., \& Doganlar, Z. B. (2016). Exogenous jasmonic acid induces stress tolerance in tobacco (Nicotiana tabacum) exposed to imazapic.Ecotoxicol Environ Saf, 124 , 470-479. doi:10.1016/j.ecoenv.2015.11.026

Kaya, A., \& Yigit, E. (2014). The physiological and biochemical effects of salicylic acid on sunflowers (Helianthus annuus) exposed to flurochloridone. Ecotoxicol Environ Saf, 106 , 232-238. doi:10.1016/j.ecoenv.2014.04.041 
Kong, J., Dong, Y., Xu, L., Liu, S., \& Bai, X. (2014). Effects of Exogenous Salicylic Acid on Alleviating Chlorosis Induced by Iron Deficiency in Peanut Seedlings (Arachis hypogaea L.). Journal of Plant Growth Regulation, 33 (4), 715-729. doi:10.1007/s00344-014-9418-0

Kong, J., Dong, Y., Zhang, X., Wang, Q., Xu, L., Liu, S., . . . Fan, Z. (2014). Effects of Exogenous Salicylic Acid on Physiological Characteristics of Peanut Seedlings under Iron-Deficiency Stress. Journal of Plant Nutrition, 38 (1), 127-144. doi:10.1080/01904167.2014.920391

Li, Q., Wang, G., Wang, Y., Dan, Y., Guan, C., \& Ji, J. (2019). Foliar application of salicylic acid alleviate the cadmium toxicity by modulation the reactive oxygen species in potato. Ecotoxicol Environ Saf, 172 , 317-325. doi:10.1016/j.ecoenv.2019.01.078

Li, Y., Long, L., Yan, H., Ge, J., Cheng, J., Ren, L., \& Yu, X. (2018). Comparison of uptake, translocation and accumulation of several neonicotinoids in komatsuna (Brassica rapa var. perviridis) from contaminated soils. Chemosphere, 200 , 603-611. doi:10.1016/j.chemosphere.2018.02.104

Li, Y., Yang, L., Yan, H., Zhang, M., Ge, J., \& Yu, X. (2018). Uptake, translocation and accumulation of imidacloprid in six leafy vegetables at three growth stages. Ecotoxicol Environ Saf, 164 , 690-695. doi:10.1016/j.ecoenv.2018.08.082

Lian, J., Zhao, L., Wu, J., Xiong, H., Bao, Y., Zeb, A., . . . Liu, W. (2020). Foliar spray of TiO2 nanoparticles prevails over root application in reducing $\mathrm{Cd}$ accumulation and mitigating Cd-induced phytotoxicity in maize (Zea mays L.). Chemosphere, 239 , 124794. doi:10.1016/j.chemosphere.2019.124794

Liang, J., \& Tang, S. (2010). Optimal dosage and economic threshold of multiple pesticide applications for pest control. Mathematical and Computer Modelling, 51 (5-6), 487-503. doi:10.1016/j.mcm.2009.11.021

Liang, L., Lu, Y. L., \& Yang, H. (2012). Toxicology of isoproturon to the food crop wheat as affected by salicylic acid. Environmental Science and Pollution Research, 19 (6), 2044-2054. doi:10.1007/s11356-0110698-7

Liu, S., Dong, Y., Xu, L., \& Kong, J. (2013). Effects of foliar applications of nitric oxide and salicylic acid on salt-induced changes in photosynthesis and antioxidative metabolism of cotton seedlings.Plant Growth Regulation, 73 (1), 67-78. doi:10.1007/s10725-013-9868-6

Liu, T., Yuan, C., Gao, Y., Luo, J., Yang, S., Liu, S., . . . Zou, N. (2020). Exogenous salicylic acid mitigates the accumulation of some pesticides in cucumber seedlings under different cultivation methods.Ecotoxicology and Environmental Safety, 198 . doi:10.1016/j.ecoenv.2020.110680

Liu, Z., Ding, Y., Wang, F., Ye, Y., \& Zhu, C. (2016). Role of salicylic acid in resistance to cadmium stress in plants. Plant Cell Rep, 35 (4), 719-731. doi:10.1007/s00299-015-1925-3

Lockridge, O., Verdier, L., \& Schopfer, L. M. (2019). Half-life of chlorpyrifos oxon and other organophosphorus esters in aqueous solution. Chem Biol Interact, 311 , 108788. doi:10.1016/j.cbi.2019.108788

Lu, Y. C., Zhang, S., Miao, S. S., Jiang, C., Huang, M. T., Liu, Y., \& Yang, H. (2014). Enhanced Degradation of Herbicide Isoproturon in Wheat Rhizosphere by Salicylic Acid. Journal of Agricultural and Food Chemistry, 63 (1), 92-103. doi:10.1021/jf505117j

Lu, Y. C., Zhang, S., \& Yang, H. (2015). Acceleration of the herbicide isoproturon degradation in wheat by glycosyltransferases and salicylic acid. J Hazard Mater, 283 , 806-814. doi:10.1016/j.jhazmat.2014.10.034

Lv, T., Zhang, Y., Casas, M. E., Carvalho, P. N., Arias, C. A., Bester, K., \& Brix, H. (2016). Phytoremediation of imazalil and tebuconazole by four emergent wetland plant species in hydroponic medium.Chemosphere, 148 , 459-466. doi:10.1016/j.chemosphere.2016.01.064

Mahapatra, K., De, S., Banerjee, S., \& Roy, S. (2019). Pesticide mediated oxidative stress induces genotoxicity and disrupts chromatin structure in fenugreek (Trigonella foenum - graecum L.) seedlings. $J$ Hazard Mater, 369 , 362-374. doi:10.1016/j.jhazmat.2019.02.056 
Mohapatra, S., Siddamallaiah, L., Matadha, N. Y., Udupi, V. R., Raj, D. P., \& Gadigeppa, S. (2019). Dissipation of neonicotinoid insecticides imidacloprid, indoxacarb and thiamethoxam on pomegranate (Punica granatum L.). Ecotoxicol Environ Saf, 171 , 130-137. doi:10.1016/j.ecoenv.2018.12.070

Namiki, S., Otani, T., Motoki, Y., Seike, N., \& Iwafune, T. (2018). Differential uptake and translocation of organic chemicals by several plant species from soil. J Pestic Sci, 43 (2), 96-107. doi:10.1584/jpestics.D17088

Noctor, G., Mhamdi, A., \& Foyer, C. H. (2016). Oxidative stress and antioxidative systems: recipes for successful data collection and interpretation. Plant Cell Environ, 39 (5), 1140-1160. doi:10.1111/pce.12726

Pasternak, T., Groot, E. P., Kazantsev, F. V., Teale, W., Omelyanchuk, N., Kovrizhnykh, V., . . . Mironova, V. V. (2019). Salicylic Acid Affects Root Meristem Patterning via Auxin Distribution in a ConcentrationDependent Manner. Plant Physiol, 180 (3), 1725-1739. doi:10.1104/pp.19.00130

Qiu, J., Chen, G., Xu, J., Luo, E., Liu, Y., Wang, F., . . . Ouyang, G. (2016). In vivo tracing of organochloride and organophosphorus pesticides in different organs of hydroponically grown malabar spinach (Basella alba L.). J Hazard Mater, 316 , 52-59. doi:10.1016/j.jhazmat.2016.05.024

Rodriguez-Serrano, M., Romero-Puertas, M. C., Zabalza, A., Corpas, F. J., Gomez, M., Del Rio, L. A., \& Sandalio, L. M. (2006). Cadmium effect on oxidative metabolism of pea (Pisum sativum L.) roots. Imaging of reactive oxygen species and nitric oxide accumulation in vivo.Plant Cell Environ, 29 (8), 1532-1544. doi:10.1111/j.1365-3040.2006.01531.x

Safari, F., Akramian, M., Salehi-Arjmand, H., \& Khadivi, A. (2019). Physiological and molecular mechanisms underlying salicylic acid-mitigated mercury toxicity in lemon balm (Melissa officinalis L.).Ecotoxicol Environ Saf, 183 , 109542. doi:10.1016/j.ecoenv.2019.109542

Song, W. Y., Peng, S. P., Shao, C. Y., Shao, H. B., \& Yang, H. C. (2014). Ethylene glycol tetra-acetic acid and salicylic acid improve anti-oxidative ability of maize seedling leaves under heavy-metal and polyethylene glycol 6000-simulated drought stress. Plant Biosystems - An International Journal Dealing with all Aspects of Plant Biology, 148 (1), 96-108. doi:10.1080/11263504.2013.878408

Song, Y., Dong, Y., Kong, J., Tian, X., Bai, X., \& Xu, L. (2016). Effects of root addition and foliar application of nitric oxide and salicylic acid in alleviating iron deficiency induced chlorosis of peanut seedlings. Journal of Plant Nutrition, 40 (1), 63-81. doi:10.1080/01904167.2016.1201491

Spormann, S., Soares, C., \& Fidalgo, F. (2019). Salicylic acid alleviates glyphosate-induced oxidative stress in Hordeum vulgare L.J Environ Manage, 241 , 226-234. doi:10.1016/j.jenvman.2019.04.035

Šudoma, M., Neuwirthová, N., Hvězdová, M., Svobodová, M., Bílková, Z., Scherr, K. E., \& Hofman, J. (2019). Fate and bioavailability of four conazole fungicides in twelve different arable soils - Effects of soil and pesticide properties. Chemosphere, 230 , 347-359. doi:10.1016/j.chemosphere.2019.04.227

Utture, S. C., Banerjee, K., Dasgupta, S., Patil, S. H., Jadhav, M. R., Wagh, S. S., . . Adsule, P. G. (2011). Dissipation and distribution behavior of azoxystrobin, carbendazim, and difenoconazole in pomegranate fruits. J Agric Food Chem, 59 (14), 7866-7873. doi:10.1021/jf200525d

Volpe, V., Marani, M., Albertson, J. D., \& Katul, G. (2013). Root controls on water redistribution and carbon uptake in the soil-plant system under current and future climate. Advances in Water Resources, 60 , 110-120. doi:10.1016/j.advwatres.2013.07.008

Wang, C., \& Zhang, Q. (2017). Exogenous salicylic acid alleviates the toxicity of chlorpyrifos in wheat plants (Triticum aestivum).Ecotoxicology and Environmental Safety, 137 , 218-224. doi:10.1016/j.ecoenv.2016.12.011

Wang, F., Zeng, B., Sun, Z., \& Zhu, C. (2008). Relationship Between Proline and Hg2+-Induced Oxidative Stress in a Tolerant Rice Mutant.Archives of Environmental Contamination and Toxicology, 56 (4), 723-731. 


\section{doi:10.1007/s00244-008-9226-2}

Wang, K., Wu, J. X., \& Zhang, H. Y. (2012). Dissipation of difenoconazole in rice, paddy soil, and paddy water under field conditions. Ecotoxicol Environ Saf, 86 , 111-115. doi:10.1016/j.ecoenv.2012.08.026

Wang, Q., Liang, X., Dong, Y., Xu, L., Zhang, X., Kong, J., \& Liu, S. (2013). Effects of Exogenous Salicylic Acid and Nitric Oxide on Physiological Characteristics of Perennial Ryegrass Under Cadmium Stress. Journal of Plant Growth Regulation, 32 (4), 721-731. doi:10.1007/s00344-013-9339-3

Wang, Q. J., Sun, H., Dong, Q. L., Sun, T. Y., Jin, Z. X., Hao, Y. J., \& Yao, Y. X. (2016). The enhancement of tolerance to salt and cold stresses by modifying the redox state and salicylic acid content via the cytosolic malate dehydrogenase gene in transgenic apple plants.Plant Biotechnol J, 14 (10), 1986-1997. doi:10.1111/pbi.12556

Xu, J., Yang, K. Y., Yoo, S. J., Liu, Y., Ren, D., \& Zhang, S. (2014). Reactive oxygen species in signalling the transcriptional activation of WIPK expression in tobacco. Plant Cell Environ, 37 (7), 1614-1625. doi:10.1111/pce.12271

Xu, L. L., Fan, Z. Y., Dong, Y. J., Kong, J., \& Bai, X. Y. (2014). Effects of exogenous salicylic acid and nitric oxide on physiological characteristics of two peanut cultivars under cadmium stress.Biologia Plantarum, 59 (1), 171-182. doi:10.1007/s10535-014-0475-9

Yu, R. P., Zhang, W. P., Yu, Y. C., Yu, S. B., Lambers, H., \& Li, L. (2020). Linking shifts in species composition induced by grazing with root traits for phosphorus acquisition in a typical steppe in Inner Mongolia. Sci Total Environ, 712 , 136495. doi:10.1016/j.scitotenv.2020.136495

Zhao, L., Huang, Y., Hu, J., Zhou, H., Adeleye, A. S., \& Keller, A. A. (2016). (1)H NMR and GC-MS Based Metabolomics Reveal Defense and Detoxification Mechanism of Cucumber Plant under Nano-Cu Stress.Environ Sci Technol, 50 (4), 2000-2010. doi:10.1021/acs.est.5b05011

Zhao, L., Zhang, H., White, J. C., Chen, X., Li, H., Qu, X., \& Ji, R. (2019). Metabolomics reveals that engineered nanomaterial exposure in soil alters both soil rhizosphere metabolite profiles and maize metabolic pathways. Environmental Science: Nano, 6 (6), 1716-1727. doi:10.1039/c9en00137a

Zhao, X. Y., Qi, C. H., Jiang, H., Zhong, M. S., You, C. X., Li, Y. Y., \& Hao, Y. J. (2020). MdWRKY15 improves resistance of apple to Botryosphaeria dothidea via the salicylic acid-mediated pathway by directly binding the MdICS1 promoter. J Integr Plant Biol, 62 (4), 527-543. doi:10.1111/jipb.12825

Zhao, X. Y., Qi, C. H., Jiang, H., Zhong, M. S., Zhao, Q., You, C. X., . . Hao, Y. J. (2019). MdWRKY46Enhanced Apple Resistance to Botryosphaeria dothidea by Activating the Expression of MdPBS3.1 in the Salicylic Acid Signaling Pathway. Mol Plant Microbe Interact, 32 (10), 1391-1401. doi:10.1094/MPMI-0319-0089-R

\section{Figure captions}

Figure. 1 The dissipation dynamic curves of CLO, DFN and DFZ after application of exogenous SA in nutrient solution. The dissipation dynamic curves of CLO, DFN and DFZ in nutrient solution without SA supplementation were shown in fig.1(A); the dissipation dynamic curves of CLO in nutrient solution with SA supplementation were shown in fig.1(B); the dissipation dynamic curves of DFN in nutrient solution with SA supplementation were shown in fig.1(C); the dissipation dynamic curves of DFZ in nutrient solution with SA supplementation were shown in fig.1(D).

Figure. 2 The dynamic distribution and accumulation of CLO, DFN and DFZ in roots, stems and leaves of cucumber plants. The dynamic distribution and accumulation of CLO, DFN and DFZ in roots, stems and leaves of cucumber plants without SA supplementation were shown in fig.2(A); the dynamic distribution and accumulation of CLO in roots, stems and leaves of cucumber plants with SA supplementation were shown in fig.2(B); the dynamic distribution and accumulation of DFN in roots, stems and leaves of cucumber plants 
with SA supplementation were shown in fig.2(C); the dynamic distribution and accumulation of DFZ in roots, stems and leaves of cucumber plants with SA supplementation were shown in fig.2(D).

Figure. 3 The effects of exogenous SA on the mean concentrations of pesticides in roots, stems and leaves of cucumber plants 28-days of exposure. The effects of exogenous SA on the mean concentrations of CLO in roots, stems and leaves of cucumber plants 28-days of exposure were shown in fig.3(A); the effects of exogenous SA on the mean concentrations of DFN in roots, stems and leaves of cucumber plants 28-days of exposure were shown in fig.3(B); the effects of exogenous SA on the mean concentrations of DFZ in roots, stems and leaves of cucumber plants 28-days of exposure were shown in fig.3(C).

Figure. 4 Effects of exogenous SA on fresh biomass (A), chlorophyll content (B), $\mathrm{H}_{2} \mathrm{O}_{2}$ content (C), proline content (D), SOD activity (E), APX activity (F), GST activity (G)and MDA content (H)of cucumber plants after roots exposure to CLO (10mg L $\left.\mathrm{m}^{-1}\right)$, DFN $\left(20 \mathrm{mg} \mathrm{L}^{-1}\right)$ and DFZ $\left(10 \mathrm{mg} \mathrm{L}^{-1}\right)$, respectively. Asterisks $\left(^{*}\right)$ indicate significant differences between the control groups and the treatment groups without supplementing SA $(\mathrm{p}<0.05)$.

\section{Tables}

Table 1

Test designs and experimental treatments code of "pesticides uptake and translocation part"

\begin{tabular}{lllll}
\hline Analyte & Without SA & SA-1mg L & SA-10mg L-1 & SA-50mg L-1 \\
\hline CLO & CLO-C & CLO-SA-1 & CLO-SA-2 & CLO-SA-3 \\
DFN & DFN-C & DFN-SA-1 & DFN-SA-2 & DFN-SA-3 \\
DFZ & DFZ-C & DFZ-SA-1 & DFZ-SA-2 & DFZ-SA-3 \\
\hline
\end{tabular}

\section{Table 2}

The half-life $\left(\mathrm{t}_{1 / 2} ; \mathrm{d}\right)$ of three pesticides in nutrient solution. Values represent the mean $\pm \mathrm{SD}(\mathrm{n}=3)$. The different letters are significantly different between the treatments $(\mathrm{P}<0.05)$ for each pesticide according to independent samples $\mathrm{T}$ test.

\begin{tabular}{llllll}
\hline Analyte & $\mathrm{t}_{1 / 2}(\mathrm{~d})$ & $\mathrm{t}_{1 / 2}(\mathrm{~d})$ & $\mathrm{t}_{1 / 2}(\mathrm{~d})$ & $\mathrm{t}_{1 / 2}(\mathrm{~d})$ & $\mathrm{t}_{1 / 2}(\mathrm{~d})$ \\
\hline & $\mathrm{C} 2$ & $\mathrm{C}$ & $\mathrm{SA}-1$ & $\mathrm{SA}-2$ & $\mathrm{SA}-3$ \\
$\mathrm{CLO}$ & $12.4 \pm 0.98 \mathrm{~b}$ & $7 \pm 0.7 \mathrm{c}$ & $5.78 \pm 0.55 \mathrm{~cd}$ & $4.07 \pm 0.92 \mathrm{~d}$ & $17.3 \pm 2.23 \mathrm{a}$ \\
$\mathrm{DFN}$ & $15.8 \pm 0.56 \mathrm{~b}$ & $11.5 \pm 0.85 \mathrm{c}$ & $9.9 \pm 0.80 \mathrm{c}$ & $6.93 \pm 0.45 \mathrm{~d}$ & $23.1 \pm 2.14 \mathrm{a}$ \\
$\mathrm{DFZ}$ & $18.2 \pm 0.8 \mathrm{a}$ & $13.8 \pm 0.98 \mathrm{~b}$ & $12.6 \pm 0.78 \mathrm{~b}$ & $5.33 \pm 0.61 \mathrm{~d}$ & $9.9 \pm 0.79 \mathrm{c}$ \\
\hline
\end{tabular}

\section{Table 3}

Mean RCF values of CLO, DFN and DFZ in cucumber plants cultivated under hydroponic conditions during 28-days of exposure. Values represent the mean $\pm \mathrm{SD}(\mathrm{n}=3)$. The different letters are significantly different between the treatments $(\mathrm{P}<0.05)$ for each pesticide according to independent samples $\mathrm{T}$ test.

\begin{tabular}{llll}
\hline Analyte & Mean root concentration factor $(\mathrm{RCF})$ & Mean root concentration factor (RCF) & Mean root concentration facto \\
\hline & $\mathrm{C}$ & $\mathrm{SA}-1$ & $\mathrm{SA}-2$ \\
$\mathrm{CLO}$ & $1.07 \pm 0.14 \mathrm{a}$ & $0.55 \pm 0.053 \mathrm{~d}$ & $0.7 \pm 0.02 \mathrm{c}$ \\
$\mathrm{DFN}$ & $0.64 \pm 0.015 \mathrm{~b}$ & $0.6 \pm 0.017 \mathrm{c}$ & $0.57 \pm 0.022 \mathrm{~d}$ \\
DFZ & $52.19 \pm 3.29 \mathrm{~b}$ & $57.4 \pm 4.76 \mathrm{a}$ & $43.92 \pm 5.77 \mathrm{c}$ \\
\hline
\end{tabular}




\section{Table 4}

Mean $\mathrm{TF}_{\text {stem }}$ and $\mathrm{TF}_{\text {leaf }}$ values of CLO, DFN and DFZ in cucumber plants cultivated under hydroponic conditions during 28-days of exposure. Values represent the mean $\pm \mathrm{SD}(\mathrm{n}=3)$. The different letters are significantly different between the treatments $(\mathrm{P}<0.05)$ for each pesticide according to independent samples T test.

\begin{tabular}{llllll}
\hline Translocation factor $(\mathrm{TF})$ & Analyte & $\mathrm{C}$ & $\mathrm{SA}-1$ & $\mathrm{SA}-2$ & $\mathrm{SA}-3$ \\
\hline \multirow{3}{*}{$\mathrm{TF}_{\text {stem }}$} & $\mathrm{CLO}$ & $0.98 \pm 0.15 \mathrm{~b}$ & $1.57 \pm 0.19 \mathrm{a}$ & $1.44 \pm 0.28 \mathrm{a}$ & $1.1 \pm 0.19 \mathrm{~b}$ \\
& $\mathrm{DFN}$ & $0.69 \pm 0.14 \mathrm{a}$ & $0.76 \pm 0.07 \mathrm{a}$ & $0.88 \pm 0.095 \mathrm{a}$ & $0.85 \pm 0.095 \mathrm{a}$ \\
& DFZ & $0.02 \pm 0.003 \mathrm{a}$ & $0.03 \pm 0.002 \mathrm{a}$ & $0.05 \pm 0.003 \mathrm{a}$ & $0.03 \pm 0.002 \mathrm{a}$ \\
$\mathrm{TF}_{\text {leaf }}$ & CLO & $8.83 \pm 0.84 \mathrm{~d}$ & $17.35 \pm 1.77 \mathrm{~b}$ & $20.27 \pm 1.81 \mathrm{a}$ & $11.6 \pm 0.83 \mathrm{c}$ \\
& DFN & $8.01 \pm 0.64 \mathrm{c}$ & $9.05 \pm 0.67 \mathrm{bc}$ & $14.16 \pm 0.67 \mathrm{a}$ & $11.53 \pm 0.79 \mathrm{~b}$ \\
& DFZ & $0.005 \pm 0.0003 \mathrm{~b}$ & $0.007 \pm 0.0004 \mathrm{~b}$ & $0.013 \pm 0.001 \mathrm{a}$ & $0.011 \pm 0.003 \mathrm{a}$ \\
\hline
\end{tabular}
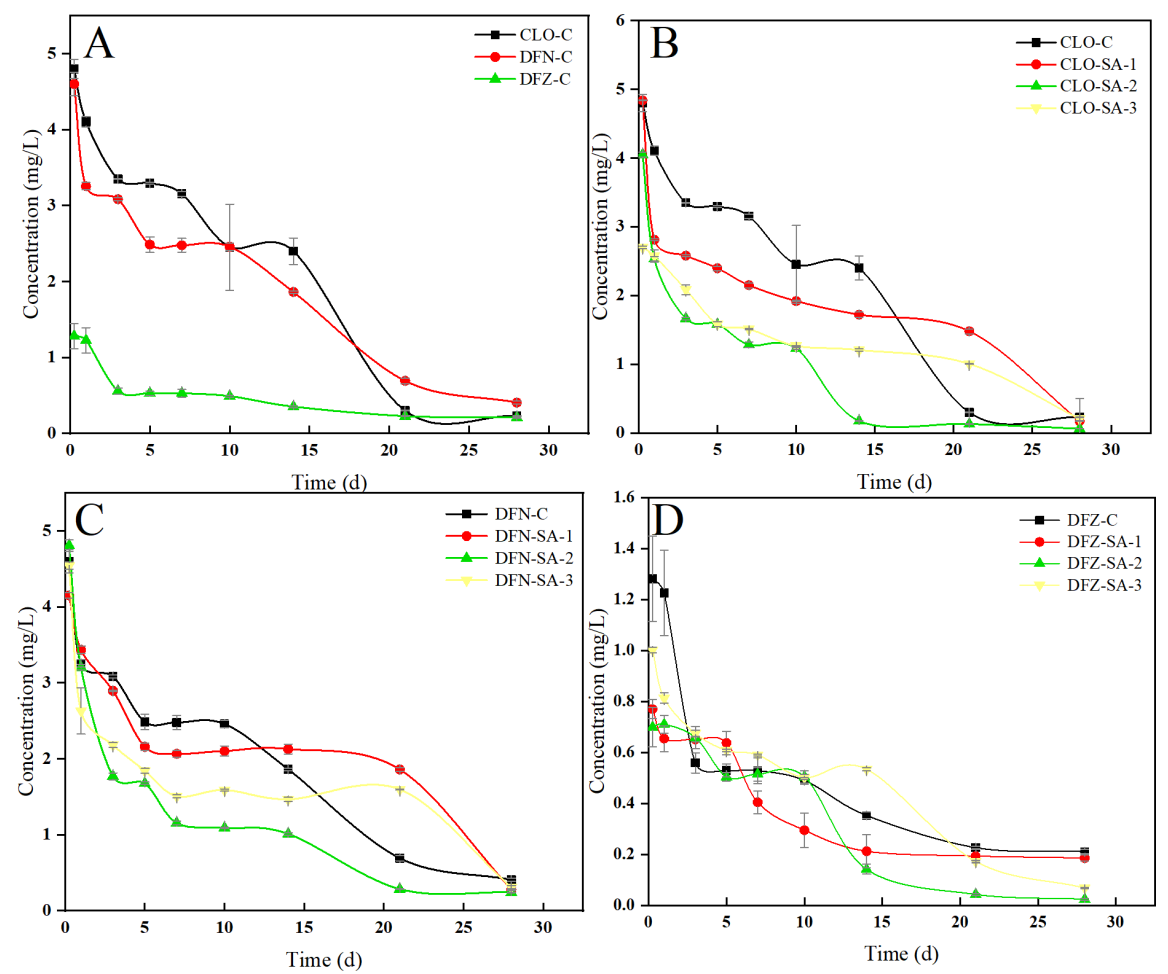